considered. It matters whether power refers to electricity or biomass. And it matters whether land is used exclusively or only partly for energy. Smil raises this issue but does not address it systemically. He could have used the concept of exergy (energy's ability to perform useful work) to differentiate between highquality energy (such as electricity, which is versatile) and low-quality energy (such as straw, which demands costly conversions to become usable beyond burning). However, his comparisons look only at power densities, irrespective of quality. Smil sketches out a valuable taxonomy of energy-related land uses along two dimensions. The first is exclusivity: the site of a power plant, for instance, is unusable for agriculture; right-of-way land underneath transmission lines is not. The second is longevity of use: a nuclear-waste repository will be in place for centuries, whereas an annual crop such as maize (corn) for conversion to ethanol can be grown in rotation. Yet Smil does not use "Cities will require vast renewableenergy hinterlands." this taxonomy, and as a result sometimes compares 'apples and oranges'.

Unlike in some of Smil's other books, the production quality of Power Density is regrettably low. I prefer readable graphics accompanied consistently by source and data referencing. In this book, many graph labels are hardly legible, and figures with references are the exception. Sometimes sources are mentioned in the text but not in the caption; at others, they are not even in the text. Graphs plot data on population and energy use, but statistical data sources are not specified or referenced.

Power Density's detailed examination of the spatial constraints of energy options adds to Smil's earlier, pioneering treatment of the subject, making it useful for energy specialists interested in exploring a massive ramp-up of renewables. But its technical nature and language make it rather inaccessible to a wider audience. And its failure to explain fundamental concepts such as the difference between power and energy, and to provide adequate data and source referencing, make it unsuitable as a textbook.

Arnulf Grubler is at the International Institute for Applied Systems Analysis in Laxenburg, Austria, and the School of Forestry and Environmental Studies at Yale University in New Haven,

Connecticut.

e-mail:gruebler@iiasa.ac.at

\title{
HUMAN EVOLUTION
}

\section{The cradle of humankind revisited}

\section{Michael Cherry catches up with new developments and old dilemmas at South Africa's hominin-fossil hotspot.}

$I^{2}$ reach the Cradle of Humankind after half an hour's drive from Johannesburg, through the Gauteng Highveld of South Africa. This open, grassy space scattered with trees is a World Heritage Site, riddled with limestone caves and hominin fossils.

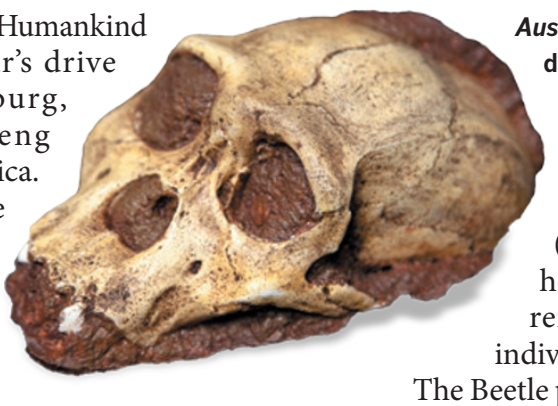

Australopithecus sediba was discovered at Malapa Cave in South Africa.

A substantial chunk of the evidence that Africa is the wellspring of humanity was discovered here; and with anthropologist Lee Berger of the University of Witwatersrand (Wits) in Johannesburg set to unearth more at the Malapa and Rising Star Cave sites, the Cradle still rocks.

As a heritage site in a developing country, the area is a focus for national pride. But developments there are spurring questions over which part of the nation they serve.

Palaeontologists will rejoice over the launch, on 21 July, of a state-of-the-art vault to house star local finds, an adjunct to Wits's Centre of Excellence for Palaeosciences. The vault will allow specimens to be compared with other finds, both hominin and nonhominin, from around Africa. These include the Taung skull (Australopithecus africanus), dated to between 2 million and 3 million years ago, which was discovered north of Kimberley in 1924; specimens of Australopithecus sediba discovered at Malapa, including a remarkably complete skeleton called MH1, as well as casts of East African discoveries such as Lucy (Australopithecus afarensis) and the type specimen of Homo habilis, found by anthropologists Mary and Louis Leakey. The vault's laboratory has a micro-CT scanner and 3D printing facilities. But it is strictly for researchers' use.

What is there for the public? The Maropeng visitor centre opened a decade ago as an interpretation centre for the Sterkfontein Caves, site of the discovery of the 'Mrs Ples' fossil (Australopithecus africanus) in 1947 and, 50 years later, Little Foot, the most complete early-hominin skeleton known, which is as-yet undescribed. And late last year, a light, moveable, steel structure known as the Beetle was placed over the Malapa site to let the paying public stone system from rain, and lets wild animals move freely below. Standing on eight clavicle-like supports, it has a fabric roof that collects rainwater and channels it to a sanitation system. Visitors will watch excavations from a raised circular walkway. A pulley below the platform is attached to a hoist capable of bearing a tonne of rock.

But there are questions over how 'public' the Beetle actually is. Costing half a million US dollars - paid for largely through the National Research Foundation (using taxpayers' money), as well as Wits and the Gauteng provincial government - the site is in a private game reserve and the tourists, when they come, will probably be rich. The Maropeng centre demonstrates this. Built at a cost of US\$29 million, it charges \$13 for admission (around half that for students), which prices out many in a country where one-fifth of the people still live on $\$ 28$ a month. That could be reflected in Maropeng's visitor numbers. Planned to accommodate 1 million visitors a year, it receives between 230,000 and 250,000 and runs at an annual loss, picked up by the provincial government. Kruger National Park, by contrast, charges different rates for South Africans and foreign tourists, and receives 1.4 million visitors annually.

Remarkable fossils continue to emerge in the Cradle, and it presents no less remarkable opportunities for palaeotourism. But a way must be found to make the specimens widely accessible. In situ interpretation of australopithecine remains should present a uniquely uplifting experience for all, rich and poor.

Michael Cherry is in the Department of Botany and Zoology at Stellenbosch University in South Africa.

e-mail:mic@sun.ac.za 